\title{
EDITORIAL
}

\section{In This Issue: Cervical Cancer Screening}

\author{
Louise S. Acheson, MD, MS, Associate Editor \\ Department of Family Medicine, Case Western Reserve University, Cleveland, Ohio
}

Ann Fam Med 2003;1:194-195. DOI: 10.1370/afm.103.

I $\mathrm{n}$ this issue of the Annals are a cluster of articles that use a variety of methods to address clinical ques-

tions about Papanicolaou (Pap) smears, among the most common screening tests performed in family practice. How could understanding women's experiences change our ways of communicating with patients whose Pap smear result was mildly abnormal? Is a speculum examination necessary for accurate collection of a sample to detect human papillomavirus (HPV)? Do most US family physicians routinely use a chaperone when they obtain a Pap smear? Are annual Pap smears so firmly entrenched that patients or clinicians might resist recommendations to reduce their frequency?

In an in-depth qualitative analysis, Karasz and colleagues ${ }^{1}$ identified 2 common outcomes when women were informed of a mildly abnormal Pap test result: emotional distress and dissatisfaction with care. Women worried about many causes of abnormal Pap smear findings, not only cancer, but also gynecologic problems and sexual behavior, which were not discussed with physicians. Uncertainty about the diagnosis is inherent to cervical cytologic screening but was interpreted by some patients as the clinician's lack or concealment of knowledge. Some women, dissatisfied by recommendations to wait for a follow-up Pap test, assumed the clinician lacked concern for them or for a potentially more urgent problem.

HPV testing is a new technology that could reduce waiting and uncertainty in the evaluation of atypia found on Pap smears. Harper and colleagues ${ }^{2}$ report on an HPV self-test using vaginal swabs. Regardless of recent intercourse, the number of days between tests, or the week of the menstrual cycle (when not bleeding), this method was as accurate as cervical HPV testing by a clinician.

Rockwell and colleagues ${ }^{3}$ analyzed data from a national survey to show that not every US family physician routinely uses a chaperone during the collection of a Pap smear. Having a chaperone present was more common in the southern United States, was much less common for female physicians, and varied inversely with the number of Pap smears per month.

$\emptyset_{\text {stbye and colleagues }}{ }^{4}$ used data from populationbased national studies to show that a substantial proportion of older American women receive Pap smears and mammograms despite recommendations suggesting that, for women of advanced age, Pap smears are unnecessary in some circumstances and the benefits of mammographic screening are unproved. Mammography rates for elderly women have increased in recent years. More educated, well-to-do, healthier women and those who visit physicians more frequently were most likely to have mammograms and Pap tests in old age.

Women's beliefs about the value of Pap smears might contradict public health recommendations for risk-based screening intervals or age limits on screening. Mindy Smith and colleagues ${ }^{5}$ used focus group interviews to explore attitudes toward reducing the frequency of Pap tests for low-risk women to once every 3 years, as recommended by the US Preventive Services Task Force and the Canadian Task Force. ${ }^{6,7}$ Most women were "firmly set" against this practice and gave a variety of reasons for believing that yearly Pap tests are desirable, including the belief that a Pap test protects general health, that some Pap tests are inaccurate and therefore need to be repeated, a suspicion that reducing the frequency of testing is motivated by concern for cost rather than quality of care, a mistrust of clinicians, and vivid personal experiences of cancer. These beliefs need to be taken into account in plans to limit a screening test that has been so well incorporated into popular culture.

This issue includes 2 other articles on important clinical topics. Somatization disorder is a challenging condition for patients and clinicians. A randomized clinical trial by Dickinson and colleagues found that providing care recommendations to family physicians improves physical but not mental functioning among patients with multisomatoform disorder. ${ }^{8}$ The effect is particularly strong among patients with comorbid chronic illnesses. 
In a community practice sample, Yawn and colleagues ${ }^{9}$ show that slow heart rate recovery after exercise stress test was not a reliable indicator of abnormality. These findings should temper the interpretation of heart rate recovery as a risk factor.

This issue concludes volume 1 of the Annals of Family Medicine. The editors thank the hundreds of colleagues worldwide who have become peer reviewers, and acknowledge the many who have so far reviewed manuscripts. This generous contribution of time and expertise is essential to the function of the Annals as a rigorous, scientific journal. Reviewers help authors improve their work and help shape this new journal's identity.

To read commentaries or to post a response to this article, see the online version at http://www.annfammed.org/cgi/content/full/1/4/194.

\section{References}

1. Karasz A, McKee MD, Roybal K. Women's experiences of abnormal cervical cytology: illness representations, care processes, and outcomes. Ann Fam Med. 2003;1:196-202.
2. Harper DM, Longacre MR, Noll WWW, Belloni DR, Cole BF. Factors affecting the detection rate of human papillomavirus. Ann Fam Med. 2003;1:221-227.

3. Rockwell P, Steyer TE, Ruffin MT IV. Chaperone use by family physicians during the collection of a Pap smear. Ann Fam Med. 2003:1: 218-220.

4. Østbye T, Greenberg GN, Taylor DH Jr, Lee AMM. Screening mammography and Pap tests among older American women 1996-2000: results from the Health and Retirement Study (HRS) and Asset and Health Dynamics Among the Oldest Old (AHEAD). Ann Fam Med. 2003;1:209-217.

5. Smith M, French L, Barry HC. Periodic Abstinence From Pap (PAP) Smear Study: women's perceptions of Pap smear screening. Ann Fam Med. 2003;1:203-208.

6. US Preventive Services Task Force. Screening for cervical cancer: Recommendations and rationale. Am Fam Physician. 2003;67:1759-1766.

7. Canadian Task Force on the Periodic Health Examination. The Periodic health examination: 2. 1987 update. CMAJ. 1988;138:618-626.

8. Dickinson WP, Dickinson LM, deGruy FV, Main DS, Candib LM, Rost K. A randomized clinical trial of a care recommendation letter intervention for somatization in primary care. Ann Fam Med. 2003;1:228-235.

9. Yawn BP, Ammar KA, Thomas R, Wollan PC. Test-retest reproducibility of heart rate recovery after treadmill exercise. Ann Fam Med. 2003;1: 236-241.

\section{CHANGE-OF-ADDRESS FORM EAMIIY MEDICMNE"}

Please complete this form and mail to the following address or fax to Annals Circulation at 913-906-6080:

Annals of Family Medicine, Circulation Department, 11400 Tomahawk Creek Pkwy, Leawood, KS 66211-2672

Check if member of sponsoring organization: $\square$ AAFP $\square$ ABFP $\square$ STFM $\square$ ADFM $\square$ AFPRD $\square$ NAPCRG

ID number from label on your journal cover

OLD INFORMATION (Please print.)

NEW INFORMATION (Please print.)

Name

Company (if applicable)

Address (Street plus Apt or Ste)

\begin{tabular}{lc}
\hline City & State \\
\hline Country & Postal Code (9-digit ZIP for US)
\end{tabular}

Telephone

Fax

E-Mail
Name

Company (if applicable)

Address (Street plus Apt or Ste)

\begin{tabular}{ll}
\hline City & State \\
\hline Country & Postal Code (9-digit ZIP for US) \\
\hline Telephone & Fax
\end{tabular}

